\title{
Inteligências Múltiplas e Representações ${ }^{1}$
}

\author{
Josset Campagna de Gáspari² \\ Universidade Estadual Paulista- Rio Claro \\ Gisele Maria Schwarts \\ Universidade Estadual Paulista- Rio Claro
}

\begin{abstract}
RESUMO - Este estudo, de revisão de literatura, teve por objetivo identificar as representações simbólicas presentes no imaginário do homem, adepto das vivências de aventura praticadas junto à natureza e, a partir disso, estabelecer analogias entre essas representações e a Teoria das Inteligências Múltiplas.
\end{abstract}

Palavras-chave: representações simbólicas; imaginário; inteligências múltiplas; vivências de aventura.

\section{Multiple Intelligences and Their Representation in Adventure Activities}

\begin{abstract}
This literature review study has as objective to identify the symbolic representations existent in man's imaginary, adept of adventure activities prachced in nature, and from this starting point, to establish analogies between these representations and the Theory of Multiple Intelligences.
\end{abstract}

Key words: symbolic representations; imagination; multiple intelligences; adventure.

Inquestionáveis são as alterações axiológicas promovidas pelo processo de globalização mundial e suas conseqüências, tanto positivas como negativas.

Dentre alguns dos benefícios decorrentes da expansão tecnológica e da automação constam a dissolução de fronteiras, o encurtamento das distâncias, a aproximação entre povos e culturas e o acréscimo do tempo excedente concedido ao homem.

Os prejuízos podem ser identificados na tendência massificadora das formas de preenchimento do tempo excedente, exercida pelo mercado, impondo ao homem uma pseudo-necessidade por produtos e serviços diversos, inclusive no que tange aos seus momentos de lazer.

O ser humano, marcado por resquícios de uma formação centrada na cultura do trabalho e do consumo, parece ser alvo vulnerável no convencimento de que lazer deva ser a recompensa pelo trabalho e de que seu tempo livre deva ser preenchido por um produto de consumo capaz de lhe proporcionar prazer, felicidade, satisfação de desejos e autorealização.

Criticamente, o homem pode vislumbrar possibilidades de escapar da homogeneização inerente a mercantilização das opções de lazer disponíveis no mercado, da rotulação, do silenciamento de seu corpo expressivo, comunicativo, criativo e ávido por experiências sensíveis e inovadoras.

Dessa forma crítica, o homem em movimento, lança-se na busca de vivências ao mesmo tempo alternativas e tam-

1 Resumo apresentado na I Conferência Nacional do Imaginário e das Representações Sociais em Educação Física, Esporte e Lazer, na Universidade Gama-Filho, Rio de Janeiro

2 Endereço: Rua Maria Madalena de Souza Campos, 248 - Alto das Araras - Araras, SP. CEP: 13.604-120 - E-mail: jossett@bol.com.br bém significativas, no sentido escapar das mazelas sociais que podem consumi-lo. Busca, então, outras possibilidades de preenchimento do seu tempo excedente na expectativa de driblar a mesmice, a rotina, os padrões de conduta socialmente esperados, resgatando sua livre escolha, sua espontaneidade, seu prazer e seu elemento lúdico.

As expectativas, presentes no homem em busca dessas alternativas, parecem explicar, pelo menos parcialmente, a crescente demanda pelas vivências de aventura junto a ambientes naturais, as quais preenchem a inquietação humana quanto à significação e inovação de suas experiências. Essas práticas alternativas podem funcionar, ainda que temporariamente, como forma de suspensão das tensões sociais presentes no seu cotidiano, linearmente pré-estabelecido, onde seu corpo convive com uma natureza que lhe é exterior e com sua subordinação ao intelecto.

Nesse pressuposto, os sujeitos envolvidos nas vivências junto à natureza têm efetivas oportunidades de rompimento com a monotonia do dia-a-dia e de auto-desafio, porque o risco controlado associado aos sabores da aventura, do ineditismo, da novidade, características nessas práticas de lazer podem lhes proporcionar sensações, emoções e percepções bastante diversas daquelas do cotidiano. Podem, também, nessas experiências, de acordo com Schwartz e De Gáspari, (2001, p. 135) "brincar" e "transgredir" os limites que lhes são impostos pela própria sociedade, os quais se traduzem na vasta gama de códigos, normas e símbolos presentes na estruturação da vida em coletividade.

Essas experiências enquanto uma das possíveis opções de lazer, evocam representações sociais porque potencializam o resgate das dimensões de liberdade, de poder, de autorealização e de auto-superação. Além disso, tais vivências estimulam o cognitivo e o imaginário como aliados no rela- 
cionamento do homem com o mundo, consigo mesmo, com sua própria natureza e com o outro.

Essa reaproximação do homem com a seu eu-natureza, oportunizada pelas atividades de lazer, vem ganhando crescente número de adeptos. As representações sociais e o imaginário subjacentes à aventura desvelam inúmeras possibilidades de resignificação do homem, da natureza, da natureza humana e do próprio tempo de lazer.

Partindo da hipótese que as imagens e símbolos, socialmente construídos, estabelecem conexões entre o homemmundo; entre o homem-homem e o homem-natureza é possível identificar, nas atividades de aventura, várias representações sociais, aqui compreendidas sob a ótica de Reigota (1995, p. 70), cujo olhar situa as representações como uma gama de princípios elaborados por grupos diversos, de modo compartilhado e interativo, as quais auxiliam a entender, interpretar e modificar a realidade onde se situam.

A primeira dessas representações pode ser descrita como sendo uma manifestação humana de resistência, a qual como sugere o termo, implica na idéia de uma força opositora a outra. Esse conceito, extrapolado para a concretização dessas vivências junto ao meio ambiente, detona imagens e símbolos de dupla ruptura com os padrões socialmente impostos: a primeira na perspectiva da abertura ao inédito, da predisposição para novas experiências e a segunda na do rompimento com a repetitividade presente nas ações diárias.

Aliás, bastante enigmática é essa relação de aparente contradição em que vive significativa parcela da população, cujo homem ao mesmo tempo em que "resiste" em jogar o jogo da sociedade, "insiste" em fazer do trabalho sua virtude maior. Insiste em fazer do seu tempo, um tempo para acumular bens e status, deixando de refletir sobre as possibilidades de "escapar" das mazelas sociais que silenciam seu corpo em movimento.

Nessa perspectiva, a "resistência" simbolizada na "aventura" pode propiciar a quem a vivencia, válvulas de escape do quadro com que se defronta e, ainda, fazer dessas atividades um confronto simbólico, qualitativo, na perspectiva das mudanças axiológicas da realidade, abarcando, inclusive, aqueles valores aos quais precisa resistir para deixar aflorar o seu eu-natureza.

Esse aflorar, dialética e dialogicamente, suscita uma segunda representação que caracteriza a relação de simbiose homem-natureza, associação que gera benefícios para ambos os envolvidos, ainda que em proporções diferentes.

A concepção de natureza admite diferentes conjecturas. Uma delas é a defendida por Gonçalves (1990), na qual o próprio conceito de natureza é determinado socialmente, corroborando para a intensificação do antagonismo natureza x cultura. Nessa relação antagônica cultura admite controle e domínio da natureza.

Outra idéia é a de Barbieri (1996), edificada numa visão antropocêntrica, segundo a qual o homem relega ou despreza tudo o que não for trabalhado por suas mãos.

Uma terceira conjectura a respeito de natureza é a de Marinho (2001), como mero local de atividades em que o praticante procura satisfação e prazer, como ambiente coin- cidentemente útil e agradável e como cenário teatral de representações de sobrevivência, no qual os indivíduos agem fora do contexto cotidiano.

As sensações que reforçam natureza como algo exterior ao movimento do corpo e do corpo em movimento, num tempo e espaço determinados, parecem ser minimizadas e/ ou revertidas durante os momentos lúdicos em contato com o meio ambiente. Ao mover-se junto à natureza, numa relação simbiótica, o ser humano tem a possibilidade de resgatar e deixar viver sua própria natureza, de evidenciar seu corpo enquanto legítimo espaço ecológico, mesmo que simbolicamente.

Desvela-se, então, a terceira das representações sociais: a ecológica. A perspectiva ecológica permite que (...) “o corpo seja tomado como o próprio espaço ecológico de realizações conscientes e onde o equilíbrio com a natureza éo sentido da busca do próprio equilíbrio interior" (Schwartz, 1999, 2000).

Nessa busca de conjugação de seus elementos internos e externos, o homem convive com as ressonâncias do fato de ser integrante e integrado à natureza, e nesse sentido, preservá-la dialeticamente implica em autopreservar-se; transgredi-la em transgredir-se, aventurar-se nela em si mesmo.

A preservação ecológica, com base em Barbieri (1996), contempla a abordagem de que o que está em jogo, não é a mera capacidade humana

de adaptação, de sobrevivência ou de perpetuação de disparidades. Vai além e inclui a perspectiva de imprimir drásticas mudanças quanto aos níveis de desenvolvimento em busca de qualidade de vida, o que tem íntima relação com o meio ambiente e com o modo pelo qual os recursos naturais são explorados.

Nas atividades significativas de lazer, em convívio com o meio ambiente, as experiências de aventura incrementam posturas mais arrojadas, onde seus adeptos têm chances de redimensionar o conceito de conservação e reiterar compromissos com seus processos de desenvolvimento.

De modo concomitante, esse vivenciar significativo pode detonar a humanidade do homem e com ela uma quarta imagem, no sentido de reaproximar e integralizar homem e natureza. A unicidade, característica do homem holístico, se evidencia na intersecção do homem-natureza, no homem harmonizado com a natureza e com a natureza humana.

Unicidade e simbiose são representações bastante próximas, pois ambas pressupõem homem-natureza como elementos interligados e interdependentes. Enquanto o processo de simbiose dilui as barreiras que separam esses elementos, a unicidade reintegra-os e devolve-lhes a humanidade.

A esse respeito, Marinho (1999) argumenta que o homem em contato com a natureza, nos momentos de livre opção pela prática de atividades de aventura, pode satisfazer seu desejo de harmonia e compromisso com a vida, de maneira criativa.

Carlos (1991), entende que é sem sentido fazer apologia à natureza negligenciando-se ou relegando-se a planos secundários a humanidade. Defende que "na sociedade virtual o ser humano social deveria, enfim, gozar da natureza e 
da sua própria natureza no seio da segunda natureza, incluindo a primeira" (p. 766).

Da unicidade decorre, então, a quinta representação, a da essencialidade humana, constituída inclusive, por parâmetros culturais, abarcando vasto repertório axiológico, simbolicamente construído e que, nem sempre, privilegiam as expressões espontâneas de algumas emoções humanas consideradas íntimas e singulares. Essa substancialidade caracteriza a individualidade humana, pautada no sentimento e na singularidade das formas de perceber o mundo.

Durante as práticas de aventura, o ser humano tem a possibilidade de dar vazão às suas angústias, medos, desejos, fantasias, esperanças, preconceitos e pré-conceitos, decorrentes da aventura de viver sob inúmeros estereótipos, sob regras inerentes aos diversos papéis sociais que assume e exerce, simultaneamente.

Ao mediar os processos de resistência, simbiose, unicidade e essencialidade, estas atividades podem, então, suscitar outras expressões e outros sentimentos espontâneos, outras percepções e sensações sublimadas dando visibilidade à sua natureza interior, ao "senso do eu" (Gardner, 1995).

$\mathrm{Na}$ visibilidade do senso do eu, conforme explicita Gardner (op cit.), ocorre a fusão dos componentes intra e interpessoais, simbolizando a globalidade das informações sobre a pessoa e funcionando como uma construção criativa que o homem faz de si para si mesmo.

Na perspectiva de resgatar-se, como ser da natureza dotado de natureza própria, o homem pode reificar a simbiose, a unicidade, a essencialidade, na tentativa de reverter o contexto predatório estabelecido a partir dos elementos axiológicos valorizados no contexto cultural, isto é, pode reinventar novas formas de sociedade. Essa capacidade humana de alterar as relações com a natureza, a partir do simbólico, desvela a sexta representação, a da catarse, a qual possibilita substituir expectativas reprimidas e canalizar as energias sublimadas.

As "atividades esportivas em ambientes naturais" conforme denomina Marinho (2000, p. 143), carregadas de simbologia, funcionam para o ser humano como forma de dar vazão às tensões e ansiedades decorrentes da realidade e, ainda, como maneira de harmonizar seu eu espontâneo com o seu eu determinado, possibilitando concebê-lo enquanto sujeito individual e social. Ambos os sujeitos descritos, os quais não são passíveis de dicotomização, podem incrementar a idéia de "se reconhecer o indivíduo sujeito de si mesmo, em oposição ao indivíduo objeto do coletivo" (Schwartz, 2000, p. 93).

Pela promoção da essencialidade, da unicidade, da simbiose, do modo de resistência e de catarse, o homem tem seus limites ampliados, o que caracteriza a sétima das representações: a da superação. A concepção de limite que permeia a superação tem imbricada a presença de uma linha demarcatória, a qual denota a existência de fronteiras nas quais o homem pode colocar à prova sentimentos e valores que norteiam suas condutas.

Ao defrontar-se com os desafios característicos desse tipo de atividades físicas como o risco (controlado), a peripécia, a proeza, a surpresa, as incertezas das conseqüências, a adrenalina, o ser humano pode explorar toda sua potencialidade e, fazendo uso de suas capacidades cognitivas, arquitetar estratégias de ação prevendo a remoção de barreiras arquitetônicas, ecológicas e pessoais que o intimidam de vivenciar, com plenitude, essas experiências.

Enquanto dotado de capacidades cognitivas, afetivas e sociais na busca da superação de situações-problema e limites, é possível inferir a existência de efeitos psicológicos saudáveis provocados pela necessidade, inerente ao homem, de preservar em suas relações sua identidade/singularidade na diversidade e sua "pluralidade na própria singularida$d e "$ (Freire, 1984, p. 40).

Para May (1982) a consciência das duas facetas que o compõem o homem como ser único, contece no instante em que faz o reconhecimento desses limites. Para esta autora, o confronto com os limites denota a expansão da personalidade humana e também que existe uma natureza complementar entre o limite e a expansão enquanto elemento da personalidade. Em outras palavras, a ampliação dos limites promove uma abertura à realidade, ao estar no mundo e com o mundo, fazendo com que o homem aprimore a pluralidade de relações pessoais, impessoais e corpóreas, as quais de forma direta são estimuladas no contato com a natureza. Uma oitava representação se revela a partir da sensitividade.

A sensitividade, presente nessas experiências tidas como incomuns, colocam seus sujeitos em constante estado de alerta, tornando-os, com isso, mais suscetíveis aos diferentes sons, cheiros e sensações provenientes do meio ambiente. Pela sensitividade, então, podem deixar fluir o ver-ouvirsentir, os ritmos internos de seu próprio corpo cuja natureza é nele contemplada. Além disso, podem apreciar, lúdica e esteticamente, aqueles elementos simples, rústicos e intensificar sua comunicação no mundo real.

Ao aguçar sua comunicação no e com o mundo real, os envolvidos nas vivências de aventura aprimoram suas perspectivas de elevarem-se para além da realidade e de transcenderem os limites de suas experiências cotidianas.

A nona representação, de transcendência, ganha visibilidade nas aventuras ecológicas através de seu praticante, pois, de acordo com Freire (1984, p. 40) "é o homem, e somente ele, capaz de transcender". Ao defrontar-se com a necessidade de não incorrer em erros que o exponham a riscos e de apresentar soluções para as imprevisíveis situações-problema, redimensiona o significado de seu próprio ser e de suas potencialidades.

Para além das experiências físicas e sensíveis, a aventura propicia oportunidades de estimulação da inteligência humana, hoje compreendida como de natureza múltipla, extrapolando sua visão tradicionalmente aceita, como sendo unidimensional.

\section{As Representações e as Inteligências Múltiplas}

A partir dos avanços da ciência cognitiva (estudo da mente) e da neurociência (estudo do cérebro) ocorrido nas últimas décadas, a inteligência humana passou por signifi- 
cativas mudanças epistemológicas e axiológicas e, em consequiência, passou da concepção singular para plural.

Nesse sentido, os estudos de Gardner $(1994,1995)$ foram decisivos para a substituição do paradigma unidimensional pelo multidimensional, onde "as múltiplas faculdades humanas são independentes em graus significativos" (Gardner, 1995, p. 29).

A Teoria das Inteligências Múltiplas, desenvolvida como uma explicação da cognição humana, além de reconhecer as diversas e independentes facetas que a compõem, ainda, preconiza a interdependência entre duas ou mais delas. Isto se explica pelo fato de que cada uma das formas de inteligência pode ser canalizada para outros fins, isto é, os símbolos vinculados àquela forma de conhecimento podem migrar para outras, denotando as características de independência e interdependência anteriormente salientadas.

Embora essa migração seja cogitada, Gardner (op cit.) reafirma essas duas características marcantes, expressandose como "convencido de que todas as inteligências têm igual direito à prioridade" (p. 15).

Essas constatações operacionalizaram-se a partir da proposta de investigação que, invertendo o curso das pesquisas até então realizadas, elegeu a resolução de problemas, como centro da metodologia, para verificar quais as possíveis capacidades implícitas na resolução dos mesmos.

A esse respeito, Antunes (1998, p. 17) esclarece que a inteligência, "tem a propriedade de selecionar a maneira melhor de compreender as coisas, a melhor saída para resolver problemas".

Inicialmente, os estudos realizados na Universidade de Harvard, numa decisão metodológica de Gardner e cols. (1995, p. 45), catalogaram uma quantidade reduzida delas, "pretendendo articular um número manejável de inteligências que parecem constituir tipos naturais", conscientes de que se as mesmas fossem tomadas em quantidades elevadas tornar-se-iam proibitivas para o teórico e inúteis para o praticante.

As sete primeiras inteligências mapeadas foram a lógico-matemática, lingüística, cinestésica-corporal, musical, espacial, interpessoal, intrapessoal. Posteriormente, com as ressonâncias do estudo e o recebimento de apoio dos órgãos de fomento norte-americanos, os mesmos se intensificaram, incorporando outras formas como a naturalista e a existencialista (Gardner, 1997).

Uma das implicações imediatas da Teoria das Inteligências Múltiplas é a explicação do porquê uma pessoa parecer mais inteligente que outra. Esse fato aparente, sob a visão gardneriana, se ancora nas diferentes oportunidades de estimulação e desenvolvimento dessas capacidades cognitivas, já que todos as detêm, igualmente, em condições potenciais.

Essa argumentação altera valores até então aceitos quanto à validade dos processos de estimulação das faculdades humanas, agora compreendidos num continuum ao longo de toda existência humana, tanto nos espaços formais como informais. É dessa forma "que os indivíduos podem diferir nos perfis particulares da inteligência com os quais nas-

cem, e que certamente eles diferem nos perfis com os quais acabam" (Gardner, 1995, p. 15).

No que concerne aos espaços informais as atividades de aventura, praticadas durante o tempo excedente, podem conferir ao homem tais possibilidades de estimulação das inteligências, de modos independente, interdependente e global.

Com os avanços da teoria gardneriana é possível inferir que do desenvolvimento dos patamares independentes da inteligência humana, podem ocorrer a promoção da inteligência global, já que melhorar uma delas tem efeitos positivos na globalidade das funções cognitivas. É possível, também, inferir que a partir do desenvolvimento das faculdades individuais pode decorrer a promoção do sujeito coletivo e da própria sociedade, a qual embute as etiologias motivadoras/detonadoras das representações simbólicas e imaginárias aqui identificadas.

Na proposta de estabelecer conexões entre as atividades de aventura junto ao meio ambiente e a Teoria das Inteligências Múltiplas, o critério adotado foi o de eleger, para cada representação, uma e apenas uma das inteligências que melhor sintetizasse as congruências identificadas neste estudo.

Essa estratégia metodológica se justifica pelo fato de que seria impossível afirmar que apenas uma das inteligências se faz presente durante os processos mentais de representação social e imaginária, sendo necessário eleger uma, dentre as demais, com o objetivo de viabilizar as analogias descritas a seguir, conforme indicado na figura1.

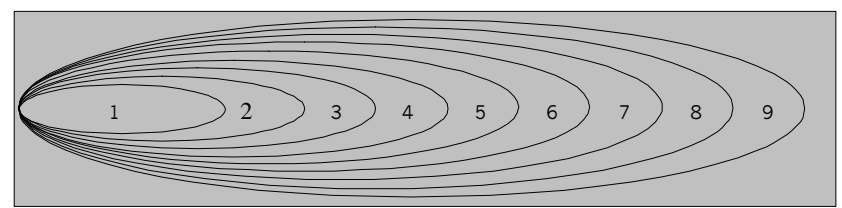

\section{INTELIGÊNCIAS}

1 - Lógico Matemática

2 - Lingüística

3 - Naturalista

4 - Interpessoal

5 - Intrapessoal

6 - Espacial

7 - Corporal-Cinestésica

8 - Musical

9 - Existencialista

\section{REPRESENTAÇÕES}

$$
\begin{aligned}
& 1 \text { - Resistência } \\
& 2 \text { - Simbiose } \\
& 3 \text { - Ecológica } \\
& 4 \text { - Unicidade } \\
& 5 \text { - Essencialidade } \\
& 6 \text { - Catarse } \\
& 7 \text { - Superação } \\
& 8 \text { - Sensitividade } \\
& 9 \text { - Transcendência }
\end{aligned}
$$

Figura 1. Representação em forma de espiral das formas de inteligência e suas representações.

\section{1 - Lógico-Matemática}

A partir do raciocínio lógico-dedutivo, o homem pode decodificar, analisar, sintetizar, compreender, avaliar e questionar os "modelos" socialmente impostos e, por meio da vivência de aventura, expressar-se resistente às perspectivas de manutenção ou de transformação desses modelos.

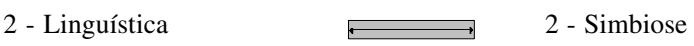


A associação homem-natureza, possibilitada nas práticas físicas junto aos ambientes naturais, estabelece uma comunicação figurada, na qual o participante pode expressar, por meio de uma linguagem própria, o rompimento das barreiras até então existentes e os benefícios dessa integração: resgate do elemento humano da sua natureza e da oportunidade do homem viver sua própria natureza.

\section{3 - Naturalista}

Vivências significativas, junto ao meio ambiente, podem possibilitar ao homem o reconhecimento dos objetos da natureza, a distinção dos elementos vegetais, animais, minerais e, simbolicamente, reconhecer-se como dotado de um corpo, com espaço ecológico integrante, integrado e integrador homem-natureza e natureza-humana.

\section{4 - Interpessoal

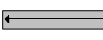 \\ 4 - Unicidade}

A capacidade de compreender o(s) outro(s), durante a "aventura" compartilhada mobiliza atitudes e valores essenciais no relacionamento (cooperação, respeito, paciência, solidariedade, empatia, reconhecimento da emoção alheia, criticidade, criatividade, encorajamento na busca de soluções sem imposição de idéias), podendo imprimir a essas experiências, um caráter único e incomparável.

$$
5 \text { - Intrapessoal }
$$

As formas singulares de perceber o mundo e perceber-se no mundo ganham visibilidade, durante as vivências junto à natureza, as quais, de modo simbólico, se traduzem no tipo de atividade escolhida, podendo revelar como o praticante se compreende, trabalha consigo mesmo e até a imagem que faz de si próprio.

A confiança, a intencionalidade, o auto-controle, a curiosidade, entre outros fatores presentes nessas práticas, podem denotar a individualidade humana obscurecida nas aparências das condutas cotidianamente esperadas.

$$
\text { 6- Espacial } \rightleftarrows 6 \text {-Catarse }
$$

A construção de um modelo mental de espaços da realidade ecológica, possibilita ao homem, utilizá-lo em sua orientação durante as vivências, tendo a oportunidade de dar vazão às suas expectativas reprimidas, provocando a substituição do eu determinado pelo eu espontâneo, dotado de natureza própria e favorecendo, ainda, a canalização de energias sublimadas.

\section{7 - Corporal-Cinestésica}

A capacidade de resolver problemas e situações inerentes às atividades de aventura, requisitam movimentos do corpo inteiro, nos quais pode estar simbolizada a própria expansão de limites do adepto, colocando-se a si próprio e também seus sentimentos, valores e concepções à prova, podendo superar as linhas demarcatórias que o inibem de viver, com plenitude, a experiência.

$$
\text { 8-Musical }
$$

A comunicação do homem no e com o mundo real, estimulada nas práticas de aventura, inclui a capacidade de utilizar sons naturais como forma de expressão. As experiências dessa natureza, pouco comuns, colocam o homem num estado de alerta, do qual decorre sua suscetibilidade para sons, cheiros, indícios, sensações, representando, simbolicamente, o ver-ouvir-sentir dos ritmos internos de seu próprio corpo, harmonizado com o exterior.

\section{9 - Existencialista}

A partir da reflexão sobre sua finitude, transitoriedade, condição de transcendência, questões inerentes à sua própria existência, o ser humano amplia as possibilidades de elevarse além da realidade cotidiana, de extrapolar os limites sociais, aos quais precisa resistir.

\section{Considerações Finais}

Com o propósito de incrementar as discussões referentes às abordagens múltiplas da inteligência, este estudo suscita a utilização da inteligência, cujo aspecto central é a necessidade de gerar questões e respondê-las (Schank \& Birnbaum, 1996, p. 88).

As questões, inteligentemente levantadas pelos sujeitos coletivos, inseridos numa cultura, perpassam pelas atitudes e valores que precisam introjetar, sob o pretexto de serem aceitos e valorizados numa determinada sociedade.

Dentre elas figuram os questionamentos críticos acerca das prementes necessidades de resistir aos padrões sociais impostos, de se resgatarem enquanto natureza integrada à natureza exterior, de harmonizarem e dar unicidade aos elementos externos e internos ao seu corpo, de se perceberem dotados de um corpo como espaço ecológico, de substituir expectativas reprimidas e canalizar energias sublimadas, de colocar à prova seus sentimentos e limites, de deixar emergir sua sensitividade para os sons, cheiros, ecos provenientes da natureza, enfim, de transcender-se.

Essas elaborações mentais, enquanto fenômeno complexo e multifacetado, nada mais são do que representações simbólicas desencadeadas e processadas pela/na inteligência humana, sendo necessário desvelá-las para compreendêlas.

Daí ser possível, pelas vivências de aventura junto à natureza, desvelar a natureza da inteligência humana e as duplas possibilidades dessas experiências: de simbolizar os questionamentos axiológicos inerentes a uma determinada sociedade e, simultaneamente, de mediar processos de desenvolvimento das faculdades cognitivas.

Nas vivências dessa natureza o praticante cria, para si próprio, respostas para as questões e situações-problema que identifica, pela cognição. Daí a importância do tratamento 


\section{J. C. Gáspari e G. M. Schwarts}

interdisciplinar do fenômeno social lazer na natureza e da natureza da inteligência humana.

Nas conexões aqui traçadas fica evidente a potencialidade que o campo do imaginário admite, enquanto conjectura, fato este que desnuda uma rica gama de aspectos físicos, sociais, psicológicos e culturais ao lado da intensidade do desafio a ser enfrentado por todos os profissionais envolvidos com o corpo em movimento.

Longe de defender verdades, o que se pretende é detonar trocas de visões, no sentido de intensificar os debates e discussões sobre esta instigante temática que conjuga representações sociais e imaginário, no âmbito das práticas corporais de aventura junto à natureza.

\section{Referências}

Antunes, C. (1998). A inteligência emocional na construção do novo eu. 3. ed. Petrópolis: Paz e Terra.

Barbieri, E. (1996). Desenvolver ou preservar o ambiente? São Paulo: Cidade Nova.

Carlos, A. F. A. (1991). O meio ambiente urbano e o discurso ecológico. In: III Encontro Nacional de Estudos sobre Meio Ambiente. (pp. 756-766). Londrina: UEL. NEMA.

Freire, P. (1984). Educação como prática de liberdade. 15. ed. Rio de Janeiro: Paz e Terra.
Gardner, H. (1995). Inteligências Múltiplas: a teoria na prática. Porto Alegre: Artes Médicas.

Gardner, H. (1997, setembro). Sobre as várias inteligências: Nova Escola, n. 105. (pp. 42-45). São Paulo.

Khalfa, J. (1996). A natureza da inteligência: uma visão interdisciplinar (Org.). São Paulo: Editora da Unesp, (UNESP/ Cambridge).

May, R. (1982). A coragem de criar. Rio de Janeiro: Nova Fronteira.

Marinho, A. (1999). Natureza, tecnologia e esporte: novos rumos. Revista Conexões: Educação Esporte, Lazer. v. 1, n. 2. (pp. 60-69). Campinas.

Marino, A. (2001). Lazer, natureza, e aventura: compartilhando emoções e compromissos. Revista Brasileira de Ciências do Esporte. v. 22, n. 2 (pp. 143-153).

Reigota, M. (1995). Meio ambiente e representação social. São Paulo: Cortez.

Schwartz, G. M. \& Silva, R. L. (1999, novembro). Lazer, turismo, ecologia: contribuições para uma nova atitude. In: Encontro Nacional de Recreação e Lazer. (pp. 418-422). Foz do Iguaçu.

Schwartz, G. M. \& De Gáspari, J. C. (2001). Risco e aventura: as representações dos limites da sociedade. In: I Conferência Nacional do Imaginário e das Representações Sociais em Educação Física, Esporte e Lazer. (p. 135). Rio de Janeiro: Universidade Gama Filho. 